University of Texas Rio Grande Valley

ScholarWorks @ UTRGV

Hipertexto

Winter 2008

\title{
Identidad y alteridad: del mito prehispánico al cuento fantástico
}

Ana Maria Morales

U.N.A.M.

Follow this and additional works at: https://scholarworks.utrgv.edu/hipertexto

Part of the Latin American Literature Commons

\section{Recommended Citation}

Morales, Ana María. "Identidad y alteridad: del mito prehispánico al cuento fantástico." Hipertexto 7 (2008): 68-76.

This Article is brought to you for free and open access by ScholarWorks @ UTRGV. It has been accepted for inclusion in Hipertexto by an authorized administrator of ScholarWorks @ UTRGV. For more information, please contact justin.white@utrgv.edu,william.flores01@utrgv.edu. 


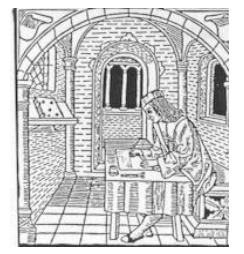

Hipertexto 7

Invierno 2008

pp. 68-76

\section{Identidad y alteridad: \\ del mito prehispánico al cuento fantástico \\ Ana María Morales \\ U.N.A.M.}

\section{Hipertexto}

U no de los temas capitales de la literatura hispanoamericana es la identidad. Aquella frágil ilusión de un mundo que se reconoce diferente, pero no parece encontrar su especificidad, ha devenido una de las obsesiones del escritor americano y lo ha llevado a buscar en las raíces de su pueblo y enfrentar éstas con la modernidad y si bien es cierto que asumir el pasado prehispánico e indígena enriquece nuestra identidad y modela cuán especiales somos, en el mundo surgido de la confrontación, del encuentro incómodo aunque fructífero de dos cosmovisiones tan diferentes, pareciera que el conflicto entre un orden prehispánico y el occidental, es, más que un choque cultural, la constatación de la insoslayable vecindad del mundo cotidiano con el de la alteridad arcaica y fantástica que subyace en todo pueblo y toda tierra de América y que no siempre nos agrada reconocer; es decir, a pesar de los intentos por asimilarlo a nuestro devenir, el pasado prehispánico, con sus mitos, con sus ritos, con sus dioses, se puede convertir en el mundo americano de hoy en la formulación de un otro amenazador que permanece oculto hasta que un intersticio de la realidad permite su vislumbre y entonces surge para mermar las certidumbres en que un sujeto moderno y occidental descansa.

Pero empecemos por el principio. Todo título es una clave de lectura. ¿Qué se puede decir entonces de "Chac-Mool" o de "Huitzilopoxtli", de "Axólotl"? Tal vez que, aun antes de empezar la lectura, estos textos están orientados a otro mundo; que estamos en el umbral de un universo que late desconocido y misterioso en esos nombres que repercuten con sonidos numinosos pero no necesariamente tranquilizadores; que se trata de textos que desde su título plantean la existencia de un mundo distinto del que habitamos. $Y$ con la posibilidad de que esos nombres evoquen un mundo otro dejándonos apenas en la frontera que lo separa del nuestro estamos cerca, muy cerca de los territorios de lo fantástico. 
Sabemos que una de las condiciones de lo fantástico es la existencia de fronteras, de límites entre sistemas de funcionamiento de realidad, códigos con los que se aprehende esa misma realidad ${ }^{1}$; es también usual anotar que la intersección de estos dos órdenes irreconciliables resulta en una trasgresión absoluta sin posibilidad de retorno, siendo ésta una ruptura que provoca escándalo, malestar, inquietud. Es por ello que traducir este conflicto a las coordenadas que plantea la búsqueda de la identidad hispanoamericana se puede convertir en una odisea del mundo claro y tranquilizador del mito al inquietante $\mathrm{y}$ amenazador del relato fantástico. Románticas en el fondo, las identidades nacionales saltan a primer plano con las independencias de los pueblos americanos y lo hacen casi al mismo tiempo que la búsqueda de las leyendas -esencial en la construcción de un pasado nacional de todos los pueblos- empiezan a devenir en la estructuración de un discurso que ya no acaricia el sueño de encontrar las respuestas en esas historias, sino de entrever el temor de no ser tranquilizados por ellas. Por este camino es que entroncan buena parte de las mitologías prehispánicas con el cuento fantástico.

Louis Vax llamó a un tema fantástico "horda de los monstruos adormecidos y de los dioses muertos" $(34)^{2}$ : seres y deidades que en algún momento de la historia formaron parte importante de un sistema mítico, y que, al desfuncionalizarse tal sistema, caen en el olvido de su status divino (o se confunden con los demonios del sistema de creencias que lo sigue) y mueren, salvo que algo o alguien los despierte. El tema es viejo, muy viejo, y es uno de los sustentos de lo maravilloso todo, no sólo de la literatura fantástica. Buena parte de las maravillas que aparecen en la literatura de ficción descansa en esta condición, ¿cuántas hadas encubren genios comarcales? ¿cuántas vírgenes cristianas encubren hadas? ${ }^{3}$ La literatura románica podría darnos muchos ejemplos de como estos dioses -germánicos, celtas, eslavosdesfuncionalizados no están del todo muertos, sino que aguardan el momento propicio para regresar y reclamar su territorio y honores o para atraer a los hombres a un mundo de deleites o terrores. Sin embargo, en un lugar y con pueblos que fueron traumática y radicalmente sometidos al cambio de sistema de creencias, y para los que han transcurrido menos años desde la adopción del cristianismo, el olvido de esas raíces aún no es fácil y la relación con ese pasado que intentó borrarse pero sólo fue soterrado sigue siendo ambigua.

Así, de la misma manera que en Europa, el tema de la alteridad numinosa amenazante ha sido recurrentemente usado por escritores de literatura fantástica: "Chac Mool", de Carlos Fuentes, narra la suplantación de un burócrata mestizo por

\footnotetext{
${ }^{1}$ Según el teórico, esos límites pueden establecerse en la oposición entre hechos a-normales, anaturales, téticos, legales o irreales y sus contrarios. Todorov habla de natural y sobrenatural; Ana Ma. Barrenechea de normal y anormal, Irene Bessiere de tético y no tético; yo lo hago de legales e ilegales.

2 Sardiñas toma este tema y lo denomina "La horda de los dioses muertos" (18-22) para referirse a objetos (estatuas) que encarnan a deidades que deberían estar muertas, pero que cuando no reciben la reverencia adecuada y son tratados sin el debido cuidado aparecen para reclamar su derecho a estar en este mundo. Uno de los ejemplos más conocidos es "La Venus de Ille" de Merimé.

${ }^{3}$ Muchas de las pervivencias prehispánicas aparecen como fenómenos paralelos a los que se dieron en la Alta Edad Media donde la victoria del cristianismo ahogó a las religiones anteriores y algunos elementos proveniente de ellas sobrevivieron, pero instalándose en la ilegalidad y a un paso de convertirse en un fenómeno de maravilla una vez desarraigadas de su función de sistemas de explicación de mundo (sobre esto último puede verse Le Goff 18-20).
} 
un ídolo acuoso que ha cobrado vida por una accidental recreación de un rito; en "Huitzilopoxtli", de Rubén Darío, y "La fiesta brava", de José Emilio Pacheco, México o la ciudad de México, subterráneos, profundos en más de un sentido, absorben a gringos descuidados que sucumben víctima de dioses supuestamente muertos; paralelamente "La noche boca arriba", de Julio Cortázar, refiere el terrible momento en que el sueño invade la realidad y un joven motociclista se convierte en víctima de los sacrificios aztecas que pretenden mantener vivo al sol, el temible dios que necesita corazones, aunque estos vengan de otro mundo; en contraste el roto sacerdote del Dios decide no cambiar la conquista y no revivir su mundo ante el descubrimiento de la palabra que lo puede todo, pues en "La escritura de Dios", de Borges, la alteridad hace, ante todo, olvidar la identidad; identidad que apenas sobrevive en "La erosión de la tinta" de Gerardo Piña ante la avalancha de cosmogonías cíclicas que absorben al hombre y lo enfrentan a la disolución de todo tiempo circular. "Axólotl", nuevamente Cortázar, parece glosar lo protéico del dios sinónimo en una pérdida ya no de una identidad individual, sino humana. Entre un inestable etcétera, "Por boca de los dioses", de Carlos Fuentes, "Rapa Nui" de Arguedas, "El caballero Carmelo", de Valdelomar o "El papagayo de Huichilobos", de Romero de Terreros, hablan del conflicto entre un orden occidental y otro prehispánico y abren la puerta a la intromisión de un sistema de realidad numinosa y diferente que termina por ser la única explicación posible ante los fenómenos acontecidos.

La relación de los pueblos americanos con su herencia prehispánica es más tensa de lo que nos gusta reconocer. Darle la espalda equivale a integrarse al mundo moderno, pero hacerlo implica renunciar a parte de los rasgos que nos hacen únicos. En esta relación esquizofrénica, el pasado que regresa, aquel pasado que desde el presente se adivina como corrupto y plagado de seres incognoscibles y dioses ajenos, se presenta ominoso e inquietante. Es por ello que cuando en el relato fantástico uno de los códigos de funcionamiento de realidad responde a los presupuestos de un orden numinoso relacionado con el mundo prehispánico, ese ayer se asume como una alteridad sobrenatural que contamina la realidad. Lo mismo en "La culpa es de los tlaxcaltecas" - de Elena Garro- que en "La noche boca arriba", la realidad diurna, civilizada y occidental termina por ser absorbida por esa otra realidad prehispánica.

Un pasado con un sistema de mitos propio y que resulta ajeno para la mayor parte de la gente sólo puede presentarse como amenazador. Dioses y mitos que, mientras permanece dormidos, son un referente elegante para marcar la identidad románticamente específica, se convierten en una amenaza a la coherencia del mundo cuando se hacen presentes en un ahora que por definición parece excluirlos. Cuando se hace posible que los mitos y los dioses de la horda no esté del todo muertos sino que estén vivos y latentes, a la espera de un momento adecuado para manifestarse y restablecer la unión de una colectividad que ha perdido el sentido de su identidad, necesariamente se produce un choque entre dos mundos -dos visiones, dos órdenes de realidad-y es entonces que surge, de la fuerza que hace desvanecerse las certezas de que el mundo es unívoco, lo fantástico.

Así, esos dos mundos, uno mítico y otro humano parecen darse la cara en muchos cuentos fantásticos, pero no lo hacen de buena gana. En "La fiebre amarilla", de Justo Sierra se puede ver la forma en que la identidad y la alteridad se dan la mano en cuanto surge lo prehispánico. El texto cuenta un viaje del narrador que 
coincide con un joven alemán. La diligencia que conduce a ambos hombres tiene que detenerse en la Sierra en medio de una tempestad y los viajeros deben pasar dos horas de furiosa lluvia intentando dormir. Cuando el narrador despierta encuentra a su compañero febril y delirante. Es entonces que el primero tiene una visión de un islote impuro del que sale una voz que le cuenta el origen de la fiebre amarilla. La voz, otro narrador, esta vez omnisciente, inmediatamente cambia el registro de la narración a un mundo de mimesis alta similar al de las leyendas (los personajes son hijos de los dioses, el tiempo en que trascurre la acción es un illo tempore al que se acude para conocer las explicaciones de porque el mundo es tal como lo conocemos, donde se instauran las leyes que desde entonces rigen el nuestro), hace un relato en el que el cuento se entrecruza con la leyenda, llena de elementos míticos taínos y palabras aztecas, que cuenta la llegada a Cuba de una niña de extraordinaria belleza que, nacida de las aguas del Golfo de México, es llevada en una concha de carey hasta las playas de la isla. Cuando se consulta al dios, éste pide que la dejen vivir y esperen a que un día regrese a las aguas. A pesar de su gran belleza, o tal vez debido a ella, Starei termina por convertirse en una plaga para los moradores de Cuba pues los hombres, hechizados por su encanto, olvidan sus templos, sus casas y familias para correr en pos de la bella sin que les importe morir. En medio de esa desdicha, llega un huracán y un hombre blanco es depositado por el mar en la playa. Starei se obsesiona con él y promete casarse con aquel que lo despierte. Todos responden que es imposible porque está muerto, pero entonces aparece Zekom, individuo misterioso, pelirrojo, tatuado y de ojos amarillos, que tras un conjuro pide a Starei que bese el cuerpo. Cuando la joven lo hace el blanco despierta y ella lo lleva a su choza y le ofrece su amor. Desgraciadamente el hombre es un sacerdote español que no puede corresponder a su pasión; además, queda el extraño Zekom transparentemente identificado como un demonio- que reclama el premio prometido y que al ver a la muchacha indecisa le ofrece una visión en la cual ellos reinan sobre las Américas y Starei -de regreso a su naturaleza numinosa- es adorada en lo alto de una pirámide. Desilusionada del español, Starei accede a los deseos de Zekom y tras entregarse a él -y ya con los mismos ojos amarillos de su amante- ve morir al sacerdote y llora por él las lágrimas ictéricas que traen las fiebres que arrebatan sobre todo a los extranjeros. "En tiempo de huracanes Starei llora más que nunca por su amado blanco y entonces todos los blancos enferman: Desde entonces, todos los años Starei lo llora sin consuelo, y sus lágrimas evaporadas por el calor del trópico se evaporan y envenenan la atmósfera del Golfo, y jay de los hijos de las tierras frías!" (441). El origen de la enfermedad queda explicado y ese relato pertenecería a un registro circular y eterno del mito que se limita a exponer las razones poéticas del malestar del alemán; empero lo fantástico se asoma para inquietar el mundo codificado como real que establemente parece separado del de la alteridad mítica cuado nos damos cuenta que el alemán en su delirio parece ver el mismo mundo del relato mítico. La otredad prehispánica reclama sus primeras vidas europeas.

En "Huitzilopoxtli. Leyenda mexicana" Darío utiliza casi la misma anécdota que setenta años después Pacheco usará en "La fiesta brava", cuando durante la Revolución mexicana y en el norte del país, su narrador presencia la tortura de Mr. Perhaps, que será sacrificado ante un ídolo que recuerda más a Coatlicue que al 
dios de la guerra florida o a Teoyaomiqui - su paralelo femenino ${ }^{4}$. El cuento es fantástico porque la anécdota es puesta en duda por la condición del narrador que está cansado, ebrio y drogado, pero la realidad del sacrificio resuena en la constatación de un mundo numinoso que sigue vivo y por ende es espantable ${ }^{5}$.

Las palabras del Coronel Reguera, el extraño cura vasco que los guía por las peligrosas tierras fronterizas, son claras: él ha aprendido a respetar a los dioses de la Tierra porque

aquí en México [...] se vive en un suelo que está repleto de misterio [...]. Y el destino de la nación mexicana está todavía en poder de las primitivas divinidades de los aborígenes. En otras partes se dice: "Rascad... y aparecerá el..." Aquí no hay que rascar nada. El misterio azteca, o maya, vive en todo mexicano por mucha mezcla social que haya en su sangre.

Las historias de la mitología parecen ser un recuento de víctimas propiciatorias. Evidentemente este sacrificio recuerda al de "La noche boca arriba", pero, aunque el más eficiente, no siempre la sangre es el camino. En el cambio del narrador de "Axolotl" en un ajolote también está presente ésta que parece ser la única manera que conocen los hombres de relacionarse con la deidad: la disolución y la entrega. El nombre que elige Cortázar, Axólotl en lugar de la forma españolizada "ajolote", hace referencia al dios Xólotl, deidad proteica, símbolo de la metamorfosis y del sacrificio renuente, que "por medio de transformaciones, resistió cuanto pudo hasta sucumbir ante el culto del sol y de la luna" (Robelo 825-828). Pertinaz caso de un dios que sucumbió ante otros dioses más nuevos justamente como esos nuevos dioses caerán ante el culto practicado por los españoles, extranjeros también, y cuyos descendientes parecen condenados a permanecer en un acuario francés tan pétreos y translúcidos como si fueran ídolos: con "total semejanza con una estatuilla corroída por el tiempo" (382) y con "la inexpresividad forzada de sus rostros de piedra" (384), pero siempre al acecho de una víctima que no intuye ancestrales, pero no los reconoce como divinos sino como monstruosos. Como el mismo texto afirma es "fácil, casi obvio, caer en la mitología" (383) para explicar la conversión.

Inquietante, pero, es cierto que entre más sangriento sea el sacrificio, más efecto tiene. En la primera parte de "La fiesta brava", de Pacheco, otro norteamericano, el capitán Keller, es entregado a Coatlicue. Keller, ex-combatiente de Vietnam y personaje de los límites, se encara al poder numinoso y aterrador de la diosa dormida en un viaje que hace a México. A la vista del monolito de Coatlicue, "madre de todas las deidades, del sol, la luna y las estrellas, diosa que crea la vida en este planeta y recibe a los muertos en su cuerpo" (70), la alteridad lo atrapa y la imagen de la estatua se convierte en una obsesión que acapara todos sus pensamientos: "usted queda imantado por ella" dice el texto. Entonces, y justo un 13 de agosto-aniversario de la caída de Tenochtitlan-, un misterioso visitante invita a Keller a conocer las entrañas de la ciudad moderna que guardan los restos de la prehispánica. Keller aparece entonces como un elegido, pues será "el primer blanco

\footnotetext{
4 "Un enorme ídolo de piedra [...] Sus cabezas de serpiente, que eran como brazos o tentáculos del bloque, se juntaban en la parte superior, sobre una especie de inmensa testa descarnada, que tenía a su alrededor una ristra de manos cortadas, sobre un collar de perlas." (86)

${ }^{5}$ Dice el narrador del sacrificio: "adquiría el espectáculo una actualidad espantable". (86)
} 
que la vea [la Piedra Pintada, la más grande escultura azteca] desde que los españoles la sepultaron en el lodo" (73). Tras el descenso al inframundo; ahí, donde la sobrenaturalidad irrumpe en el paradigma de la realidad del capitán, se consumará la inversión de leyes cuando lo lleven a la piedra de sacrificios para sacarle el corazón. Otra vez el corazón del extranjero como fruto que mantiene viva a una deidad de la horda que reaparece y se manifiesta viva y poderosa, con oficiantes que raptan incautos, para continuar con prácticas religiosas que fueron erradicadas por el cristianismo.

La modernidad y el mundo antiguo frente a frente. Vieja confrontación tan cara a lo fantástico y que se reactualiza en los textos para ver ganar casi siempre a lo atávico: Laura -en "La culpa es de los Tlaxcaltecas"-, seducida por el poder del tiempo perdido y encauzada a un intercambio de mundos donde la realidad que se había manejado como diegética pasa a una metadiégesis y la alteridad toma su lugar para que el personaje regrese al sitio que, al parecer, le corresponde. El perfectamente integrado Ciro Doral oye la llamada de lo indígena en una quena y, aunque completamente horrorizado, es fascinado fatalmente por la otredad hasta convertirse en parte de ella, una figura "casi geológica" y tan elemental como la montaña (Agrait 401). Igual en "Alta montaña", de Soler Frost, donde Patrocinio Greene sube al Popocatépetl y asistimos a su dudoso rapto por parte de seres que recuerdan a guerreros aztecas. Este rapto, este cambio de realidad, puede ser el castigo que los dioses de la horda reservan a los que depredaron a sus pueblos, pero también a aquellos que fueron su pueblo y ahora los han olvidado.

En "Chac Mool", uno de los más famosos cuentos de Carlos Fuentes -y de la horda- Filiberto compra una estatua del dios Chac, divinidad del agua vertical y masculina. El comprador la lleva su casa y la coloca en el sótano. Entonces comienzan los fenómenos extraños: las tuberías se rompen y el sótano queda inundado; el agua de lluvia penetra en la casa. "Es la primera vez que el agua de las lluvias no obedece a las coladeras y viene a dar a mi sótano" (16), dice Filiberto dando cuenta de la ruptura de un orden natural que parece ser suplantado por un sistema de reglamentación del mundo que no corresponde con que él conoce: el agua ya no está regida por las leyes físicas y aceptables en el paradigma de realidad del personaje (la muy modesta ley que dice que el agua de la lluvia debe deslizarse a las coladeras, está rota), ahora aparece regida por un sistema misterioso que sólo podría tener una explicación: está siendo atraída por la estatua (explicación ilegal desde el paradigma de realidad vigente para el personaje cuando empieza el cuento). Es decir, poco a poco el sistema de reglas naturales está siendo suplantado por otro. En un ambiente tan propicio como el sótano inundado, la figura de piedra del dios del agua va adquiriendo características humanas y finalmente se anima: "Allí estaba Chac Mool, erguido, sonriente, ocre, con su barriga encarnada. Me paralizaban los dos ojillos, casi bizcos, muy pegados a la nariz triangular [...]. Chac Mool avanzó hacia la cama; entonces empezó a llover". (20-21)

La utopía de lo prehispánico en América es eso, una utopía, porque el pasado nunca regresa y todo intento por recrearlo nos coloca en una ilegalidad capaz de romper el mundo precariamente construido sobre sus ruinas. Filiberto, como tantos personajes de cuento fantástico, no desconoce del todo la peligrosa herencia prehispánica del ídolo ya que es un coleccionista. Pero no es un respetuoso sacerdote que recree un ritual prehispánico en un intento de despertar a su dios; es un mestizo y su vida está más cerca de lo occidental que de lo prehispánico, es por 
ello que la aparición de la alteridad encarnada en el dios antiguo no puede sino alterar -destrozar- el suyo. Lo interesante es que en un principio el Chac se manifiesta con todos sus atributos numinosos y acuáticos. Invade no sólo el sótano, sino su mundo, primero la habitación, después la casa, al parecer el vecindario y, finalmente, toma como tributo su vida en el sacrificio final de la muerte por ahogamiento. Sin embargo, lo curioso en este cuento es que cuando el cuerpo de Filiberto regresa a su hogar, el narrador nos informa de un indio perfumado y en bata de seda que abre la puerta. En efecto, Filiberto provocó a un dios que, fiel a su naturaleza, exigió su vida para independizarse del que lo había despertado, pero en lugar de usar esa independencia para restaurar no sólo sus poderes sino sus costumbres, el Chac intenta, como tantos mestizos e indígenas de la América Latina, olvidar su pasado y adopta la parodia de cultura occidental representada en la bata, el maquillaje y el perfume. No olvidemos que, finalmente, también el sacerdote de "La escritura de Dios", decide dejar que su mundo agonice para integrarse a una realidad más codiciada.

Es cierto que América heredó muchos rasgos del imaginario mítico anterior al nuevo imaginario mestizo, pero en muchos casos lo transformó de un sistema de creencias tranquilizador y operativo en una oscura red de significados que permanecen ajenos a las personas y por ello misteriosos, de modo que cuando se encuentran frente a algún fenómeno que podría explicarse con leyes religiosas previas no pueden evitar la desazón. ¿Qué mejor entrada necesita lo fantástico? En cuentos como los que he mencionado lo prehispánico es otro por muchas razones. Uno de los grandes mitos de América es la confianza en la vigencia de su pasado prehispánico. Y mientras se le da la espalda a lo indígena actual, una y otra vez se buscan y encuentran las justificaciones para los problemas y las victorias sociales en un mundo anterior a la llegada de los occidentales a tierra americanas, sin embargo, en muchas ocasiones ese pasado ideal se niega, o se convierte en una constatación menos satisfactoria de lo que pareciera un discurso oficial ${ }^{6}$. Los vaivenes de la América Latina entre reconocer la deuda con su pasado y negarlo es uno de los lugares comunes a los que se acude en casi cada reflexión sobre la identidad de los pueblos americanos.

Hay que recordar que un mito tiende a explicar y tranquilizar en tanto que un texto fantástico a lo contrario. El pasado en un mito es el espacio donde se encuentran las razones que explican nuestro mundo, pero en un cuento fantástico el pasado es una ominosa alteridad que acecha un descuido de la razón para destruirla. Independientemente de cual sea la postura oficial sobre la construcción de la identidad nacional, en el imaginario de muchos pueblos americanos pueden imperar las costumbres antiguas, pero en esa colonización plena del sistema de creencias lo prehispánico, lo mítico prehispánico, surge como una peligrosa alteridad que merma el mundo, devora las certezas y puede desestabilizar incluso la propia identidad de los pueblos, así que más vale recordar que el pasado, por más que lo

\footnotetext{
${ }^{6}$ De la misma manera en que lo prehispánico es invocado para resistir a la integración, también es temido y exorcizado como un mal ancestral y una herencia de corrupción por quienes han pretendido integrarse mejor a la cultura occidental. Valga un sólo ejemplo: en 1929 Tablada no duda en afirmar que males como el analfabetismo y "la ausencia de ideales éticos y normas espirituales". (3)
} 
deseemos, nunca vuelve, que perderse en él es peligroso, que acercarse a la horda es una aventura que puede conducir a morir "Por boca de los dioses".

\section{Obras citadas}

AGRAIT, Gustavo (2003). "El extraño caso de Ciro Doral". En: J.M. Sardiñas y A.M. Morales (eds.) Relatos fantásticos hispanoamericanos. Antología. La Habana: Casa de las Américas, pp. 395-407.

BARRENECHEA, Ana María (1972). "Ensayo de una tipología de la literatura fantástica (A propósito de la literatura hispanoamericana)". Revista Iberoamericana, 38, pp. 391-403.

BESSIĖRE, Irène (1974). Le récit fantastique. La poétique de l'incertain. Paris: Larousse.

CORTAZAR, Julio (1994). "Axólotl". En: Cuentos completos. 1. Madrid: Alfaguara, pp. 381-385.

DARÍO, Rubén (1979). "Huitzilopoxtli. Leyenda mexicana". En: Cuentos fantásticos. Ed. José Olivio Jiménez. Madrid: Alianza, pp. 81-87.

FUENTES, Carlos (1973). "Chac Mool”. En: Los días enmascarados. México: Era, pp. 9-27.

LE GOFF, Jacques. "Le merveilleux dans I'Occident médiéval". En: L'Imaginaire Médiéval. Essais. 2a. ed. Paris: Gallimard, 1991. 17-39.

MORALES, Ana (2004). "Transgresiones y legalidades. Lo fantástico en el umbral". En: A.M. Morales y J.M. Sardiñas (eds.) Odiseas de lo fantástico. México: Coloquios Internacionales de Literatura Fantástica, pp. 25-37.

PACHECO, José Emilio (1997). "La fiesta brava". En: El principio del placer. México: Era, pp. 65-98.

ROBELO, Cecilio A. (1980). Diccionario de mitología náhuatl. 2 ts. México: Innovación.

SARDIÑAS, José Miguel (2002). Los objetos fantásticos. Puebla: Universidad Autónoma de Puebla.

SIERRA, Justo (1977). "La fiebre amarilla". En: Obras completas, II. Prosa Literaria. Cuentos románticos. México: UNAM, pp. 436-442.

TABLADA, José Juan (1929). "Huichilobismo". El Universal, 25 abril, p. 3.

TODOROV, Tzvetan (1970). Introduction à la littérature fantastique. Paris: Seuil. 
VAX, Louis (1974). L'art et la littérature fantastiques. 4a. ed. Paris: PUF. 